\title{
Identification of multiple disease resistant maize accessions
}

\author{
V.K. MALIK ${ }^{*}$, ROBIN GOGOI ${ }^{2}$, K.S. HOODA ${ }^{3}$ and M. SINGH ${ }^{4}$ \\ ${ }^{1}$ CCS Haryana Agricultural University, Regional Research Station, Karnal 132 001, Haryana, India \\ 2ICAR-Indian Agricultural Research Institute, New Delhi 110 012, India \\ ${ }^{3}$ ICAR-Indian Institute of Maize Research, Pusa Campus, New Delhi 110 012, India \\ ${ }^{4}$ Department of Plant Pathology, CCS Haryana Agricultural University, Hisar 125 004, Haryana, India
}

Received: 29 August 2016/ Accepted: 04 October 2016/ Published online: 23 March 2017

(C) Indian Phytopathological Society 2017

\begin{abstract}
Maize (Zea mays $\mathrm{L}$; $\mathbf{2 N}=20$ ) is an important cereal crops of the country and grown over an area of 8.67 million ha. Maize is grown in more than $\mathbf{1 5 0}$ countries and contributes a lot to nutritional food security of the society. Maydis leaf blight and Banded leaf and sheath blight diseases are the most important foliar diseases of kharif season causing immense losses in yield. Both the diseases are of high damaging potential, so large number of normal maize hybrids of different maturity groups along with specialty corn hybrids were screened against both the diseases during kharif 2014 under artificial inoculation conditions at Karnal and Delhi. In late maturity group, one hybrid namely DAS-MH-105 was observed as resistant to MLB and BLSB based on average of both the locations. Twelve hybrids including HM 8-C, DKC 9144 (IM8478), AQH 9 and Kuber Shakthi were recorded as moderately resistant for normal maize of medium maturity group. Seven and three hybrids exhibited moderately resistant reaction for early and extra early group, respectively. CMH 10-531 of early maturity group was found moderately susceptible to both the diseases. In case of specialty corn hybrids including VEHQ 11-1 and HQPM1C for quality protein maize; HPC 1 and BPC 3 for pop corn; ADVSW-1 and Bisco MaDHAU for sweet corn and BVM-2 for baby corn were registered under moderately resistant category against MLB and BLSB diseases, while few of pop corn hybrids showed moderately susceptible reaction.
\end{abstract}

Keywords: Banded leaf and sheath blight, maydis leaf blight, resistance

Maize is one of the most important crops of the world and contributes a lot to food security in developing countries. Maize is grown in more than 150 countries but the major maize producing countries are USA, China, Brazil, Mexico, France and India. In India, maize occupies an area of 8.67 million hectares having production of 22.26 million tones with an average productivity of 2.57 t/ha. In Haryana, the crop occupies an area of 9.0 thousand hectares having production of 26 thousand tones with an average productivity of $2.56 \mathrm{t} / \mathrm{ha}$ (Anonymous, 2015). It is being used as feed ( 63 per cent), food (23 per cent), starch industries (12 per cent), seed and miscellaneous uses (2 per cent) in India. This crop has been basic food for Mexico, Central America and Latin America. There is increase in demand and area under cultivation of specialty corn viz. quality protein maize (QPM), pop corn (PC), sweet corn (SC) and baby corn $(B C)$ along with normal yellow maize. The content of two essential amino acids i.e., lysine and tryptophan in QPM is very high as compared to normal maize. Therefore, quality protein maize (QPM) is essential for improvement of the nutritional quality of daily diet. Use of maize as feed, food, fodder and specialty corn as pop corn, sweet corn, baby corns makes it one of the main crops par excellence for industrial use adapted to different agro-ecological and climatic conditions.

*Corresponding author: vmexcel@ rediffmail.com
The maize diseases of global importance that pose threats to maize yield and human health includes the fungal pathogens that attack the leaves, stem and ear (Balint-Kurti and Johal, 2009). Maydis leaf blight caused by Bipolaris sorokiniana (telomorph: Cochliobolus heterostrophus) is a serious fungal disease of maize throughout the world where maize is grown under warm and humid conditions (White, 1999). It has now become one of the most prevalent and severe diseases in countries like Pakistan, India, Nepal, Indonesia, Vietnam and China. In India the crop grown in kharif season is prone to number of biotic factors like foliar diseases, stalk rots, and sheath blight where maydis leaf blight is the most important foliar disease in maize growing areas. Now a day's incidence of banded leaf and sheath blight is also increasing in maize growing areas of the country. Both the diseases are well noticed in Jammu \& Kashmir, Himachal Pradesh, Punjab, Rajasthan and Delhi and Haryana. Maydis leaf blight caused by $B$. sorokiniana causes considerable losses in production and productivity of the crop. The worldwide crop losses due to maize diseases have been estimated at 4 to 14 per cent of annual global harvest (Oerke, 2006). The disease BLSB incited by Rhizoctonia solani f.sp. sasakii has a potential to inflict the economic losses up to 100 per cent (Sharma et al., 2002). This disease has attained damaging status and has rapidly gained economic importance in several parts of the world (Kumar and 
Singh, 2004). So, the present investigation was carried out at two locations to find the resistance in normal and specialty corn hybrids against both the diseases.

\section{MATERIALS AND METHODS}

The present study was conducted at CCS Haryana Agricultural University regional research station, Karnal and research farm, ICAR-Indian Agricultural Research Institute, New Delhi. A total of ninety four hybrids of normal maize of different maturity groups [Late Maturity (27), Medium Maturity (31), Early Maturity (26) and Extra Early Maturity (10)] and forty eight of specialty corn were sown at both the locations in the month of July during kharif 2014 in a paired row system with the row length of $4 \mathrm{~m}$, spaced at $60 \times 20 \mathrm{~cm}$. The crop was raised by following all recommended practices, where recommended dose of fertilizer was applied and weeding was done manually. Two spreader rows with mixture of genotypes HKI 1105 and HKI 536 CBT were planted on either side of the screening material and used as susceptible check to MLB and BLSB at Karnal. At Delhi CM 600 and CM 501 were used as susceptible check for MLB and BLSB, respectively. The MLB inoculum was collected from previous years naturally infected leaves and sorghum grain culture method (Singh et al., 2004) was used to inoculate the plants at $40-45 \mathrm{~cm}$ height in case of maydis leaf blight. At both the locations local isolates were used for inoculation. In case of BLSB, the infected plant parts were collected from previous/current years naturally infected plants and the moist sheath blight infected plant bits were placed at the junction of sheath and lower leaf. The diseases were rated at dough stage on 1-5 scale where 1.0 was for highly resistant, 1.1-2.0 for resistant, 2.1-3.0 for moderately resistant, 3.1-4.0 for moderately susceptible and 4.1 -5.0 for susceptible (Payak and Sharma, 1985; Shekhar and Kumar, 2012).

\section{RESULTS AND DISCUSSION}

The reaction of one hundred and forty two maize hybrids against maydis leaf blight and banded leaf and sheath blight at both the locations was recorded at dough stage of the crop. The results are presented as under:

\section{Normal maize hybrids}

In late maturity group twenty seven hybrids were tested for their reaction to MLB and BLSB. The disease reaction recorded in the range of 1.8 to 3.1 (MLB) and 2.0 to 4.2 (BLSB) on 1-5 disease rating scale (Table 1). Only one hybrid namely DAS-MH-105 was observed as resistant to both MLB and BLSB, while fourteen hybrids including VNR 31834, HTMH 5108, HTMH 5202, HTMH 5404, $\mathrm{KMH}-2811, \mathrm{RMH}-972$, JH 12247, Bio 032 (BB032), CP999, JANHIT, LTH-22, NMH-1265, PMH 1-C and Seedtech 2324 exhibited the disease score between 2.1 to 3.0 , hence rated as moderately resistant to both the diseases. The hybrids DKC 9141(IM 8539) and Siri 4527 exhibiting resistant reaction to MLB were observed as moderately susceptible to BLSB. Bio -9681 was found susceptible to BLSB.
In medium maturity group none of the hybrid was found resistant to BLSB whereas, fourteen hybrids were registered under resistant category in case of MLB (Table 1). Out of thirty one hybrids, twelve hybrids namely DKC 9144 (IM8478), FCH 11231, AQH 9 Kuber Shakthi, CMH 11-617, EH-2205, KMH-5951, PRMH-2177, Rasi-3033, $\mathrm{PMH} 4$, HM 4 and HM 8 exhibited moderately resistant reaction against both the diseases. Hybrid namely $\mathrm{TH}$ 38 exhibiting resistant reaction against MLB was found moderately susceptible to BLSB. Similarly, 26 hybrids of early maturity group exhibited different kind of reaction against both the diseases (Table 2). Hybrids namely $\mathrm{FH}$ 3669, Bio 9720, CMH 11-611, CMH 11-626, B-52, EH2214, NMH-1258, JH-31613 and EH-2212 were resistant to MLB disease, whereas none of the hybrid was found resistant to BLSB disease. Seven hybrids namely $\mathrm{FH}$ 3664, JH-31610, MEH 1-12-13, CMH 11-579, CMH 11629, HKH 341 and EH-2233 exhibited a disease score between 2.1 to 3.0 against both the diseases. CHM -531 was found moderately susceptible to both the diseases. Ten hybrids of extra early maturity group were also tested against both the diseases. Here three hybrids namely $\mathrm{AH}-1212, \mathrm{KH}-7502$ and $\mathrm{HM}$ 10-F exhibited multiple disease resistance (Table 2). BIO 9681- $\mathrm{F}$ was rated as moderately susceptible to both the diseases among hybrids of extra early maturity group.

\section{Specialty corn hybrids}

Average disease score of QPM, pop corn, sweet corn and baby corn hybrids is presented in Table 3 . The results indicated that the disease reaction occurred in the range of 1.5 to 3.5 (MLB) and 2.3 to 4.0 (BLSB), when recorded on 1-5 scales. The evaluated germplasm exhibited different kind of reactions against both the diseases. Among the sixteen QPM hybrids, four hybrids viz. BQPMH- 17, LQPMH 11-6, DMRQPM 1401 and Vivek QPM-9 exhibited disease score of 1.1 to 2.0 (MLB), hence these hybrids were rated as resistant. Eight QPM hybrids including LQPMH 114, LQPMH 214, LQPMH 314, VEHQ 11-1, DMRQPM 1401, HQPM 1, HQPM 4 and HQPM 5 were rated moderately resistant to BLSB. Hybrids namely Vivek QPM-9 exhibiting moderately resistant reaction to MLB was found moderately susceptible to BLSB. Four hybrids viz. VEHQ 11-1, HQPM 1, HQPM 4, HQPM 5 were as moderately resistant to both the diseases. Out of nine pop corn hybrids, five hybrids each were found moderately resistant to MLB and BLSB, while four hybrids namely BPC 3, BPCH 27, VL Pop Corn-2, HPC 1 exhibited multiple resistance. Bajaura Popcorn-2, DMRHP 1402, VL Pop corn were found moderately susceptible to both the diseases. In case of sweet corn, 15 and 7 hybrids were observed as resistant to moderately resistant against MLB and BLSB, respectively. ADVSW-1, Bisco MaDHAU, BSCH 63, SWC 001, MADHAURI, and WOSC exhibited disease score between 2.1 to 3.0 for both the diseases. In case of baby corn, eight hybrids were tested where only one hybrid namely $\mathrm{CMH}$ 11-658 was found resistant to both the diseases. Five baby corn hybrids viz. $\mathrm{CMH} 11-659$, NP 5004, NP 5040 Vivek Hybrid-27 and HM 4 were observed 
Table 1. Performance of different maize hybrids of late and medium maturity group to MLB and BLSB diseases over the locations

\begin{tabular}{|c|c|c|c|c|c|c|}
\hline \multirow[t]{2}{*}{ Genotype (LM) } & \multicolumn{3}{|c|}{ MLB Score } & \multicolumn{3}{|c|}{ BLSB Score } \\
\hline & Karnal & Delhi & $\overline{\text { Average }}$ & Karnal & Delhi & Average \\
\hline VNR 31834 & 2.8 & 2.0 & 2.4 & 2.2 & 3.0 & 2.6 \\
\hline X 35D601 & 1.8 & 2.0 & 1.9 & 2.1 & 3.0 & 2.6 \\
\hline DKC 9133(IM9133) & 2.6 & 2.0 & 2.3 & 3.2 & 3.0 & 3.1 \\
\hline DKC 9141 (IM8539) & 2.0 & 1.5 & 1.8 & 3.6 & 3.0 & 3.3 \\
\hline НТМH 5108 & 2.7 & 2.0 & 2.4 & 1.7 & 3.5 & 2.6 \\
\hline HTMH 5202 & 2.1 & 2.0 & 2.1 & 2.2 & 2.5 & 2.4 \\
\hline HTMH 5404 & 2.2 & 2.0 & 2.1 & 2.1 & 3.5 & 2.8 \\
\hline KMH-2811 & 2.5 & 2.0 & 2.3 & 1.8 & 3.0 & 2.4 \\
\hline RMH-972 & 2.5 & 2.5 & 2.5 & 2.0 & 3.0 & 2.5 \\
\hline SUPER GA-105 & 2.8 & 2.0 & 2.4 & 3.6 & 2.5 & 3.1 \\
\hline VNR 31355 & 2.9 & 2.0 & 2.5 & 4.3 & 3.0 & 3.7 \\
\hline Siri 4527 & 1.7 & 2.0 & 1.9 & 4.0 & 3.0 & 3.5 \\
\hline JH 12247 & 3.1 & 2.0 & 2.6 & 2.4 & 3.0 & 2.7 \\
\hline Вiо 032 (ВВ032) & 2.9 & 2.0 & 2.5 & 2.3 & 3.0 & 2.7 \\
\hline IM 8562 & 2.6 & 2.0 & 2.3 & 2.0 & 2.0 & 2.0 \\
\hline CP. 999 & 2.8 & 2.0 & 2.4 & 3.0 & 2.0 & 2.5 \\
\hline DAS-MH-105 & 2.0 & 2.0 & 2.0 & 1.0 & 3.0 & 2.0 \\
\hline IM 8556 & 2.4 & 2.0 & 2.2 & 3.3 & 3.0 & 3.2 \\
\hline JANAHIT & 2.4 & 2.0 & 2.2 & 2.5 & 2.0 & 2.3 \\
\hline PRO-392 & 2.0 & 1.5 & 1.8 & 2.4 & 2.0 & 2.2 \\
\hline LTH-22 & 2.5 & 2.5 & 2.5 & 1.9 & 3.0 & 2.5 \\
\hline NMH-1265 & 2.7 & 1.5 & 2.1 & 3.0 & 2.5 & 2.8 \\
\hline Geo Primium Diamond & 2.0 & 2.0 & 2.0 & 2.6 & 2.5 & 2.6 \\
\hline $\mathrm{PMH} 1$ & 2.2 & 2.0 & 2.1 & 3.0 & 2.5 & 2.8 \\
\hline PMH 3 & 3.0 & 2.5 & 2.8 & 3.9 & 2.5 & 3.2 \\
\hline Bio -9681 & 3.6 & 2.5 & 3.1 & 4.4 & 4.0 & 4.2 \\
\hline Seedtech 2324 & 2.2 & 2.0 & 2.1 & 2.0 & 3.5 & 2.8 \\
\hline RES. CHECK & 1.2 & - & 1.2 & 1.9 & - & 1.9 \\
\hline SUS. CHECK & 4.0 & 5.0 & 4.5 & 4.4 & 4.0 & 4.2 \\
\hline \multicolumn{7}{|l|}{ Genotype (MM) } \\
\hline LG 32.82 & 1.6 & 2.5 & 2.1 & 3.2 & 3.5 & 3.4 \\
\hline $\mathrm{AQH} 4$ & 2.3 & 2.0 & 2.2 & 3.1 & 3.0 & 3.1 \\
\hline CMH 10-547 & 2.0 & 2.0 & 2.0 & 3.0 & 2.5 & 2.8 \\
\hline DKC 9144 (IM8478) & 1.7 & 2.5 & 2.1 & 1.8 & 3.0 & 2.4 \\
\hline DKC 9149 (IM8581) & 2.2 & 2.5 & 2.4 & 3.3 & 3.0 & 3.2 \\
\hline $\mathrm{FCH} 11231$ & 2.5 & 2.0 & 2.3 & 3.4 & 2.5 & 3.0 \\
\hline JKMH 4545 & 1.8 & 2.0 & 1.9 & 2.3 & 3.0 & 2.7 \\
\hline S-6750 & 2.0 & 2.0 & 2.0 & 2.6 & 3.0 & 2.8 \\
\hline TH-38 & 1.8 & 2.0 & 1.9 & 3.4 & 3.0 & 3.2 \\
\hline AQH 9 & 2.1 & 2.0 & 2.1 & 2.2 & 3.5 & 2.9 \\
\hline СMH 11-582 & 1.4 & 1.5 & 1.5 & 2.1 & 2.5 & 2.3 \\
\hline DKC 8144 (IM 8479 ) & 2.0 & 2.0 & 2.0 & 2.2 & 3.0 & 2.6 \\
\hline Kuber Shakthi & 2.2 & 2.0 & 2.1 & 2.4 & 2.5 & 2.5 \\
\hline AQH 8 & 2.2 & 2.5 & 2.4 & 2.5 & 4.0 & 3.3 \\
\hline HTMH 5402 & 1.7 & 1.5 & 1.6 & 2.2 & 3.0 & 2.6 \\
\hline BH 41150 & 1.8 & 2.0 & 1.9 & 2.8 & 3.0 & 2.9 \\
\hline CMH 11-617 & 1.6 & 2.5 & 2.1 & 2.4 & 2.5 & 2.5 \\
\hline EH-2205 & 2.1 & 2.0 & 2.1 & 2.5 & 3.0 & 2.8 \\
\hline EH-2240 & 2.0 & 2.0 & 2.0 & 2.1 & 3.0 & 2.6 \\
\hline EHL 3412 & 1.6 & 1.5 & 1.6 & 1.8 & 2.5 & 2.2 \\
\hline KMH-5951 & 2.6 & 2.0 & 2.3 & 2.5 & 3.0 & 2.8 \\
\hline PRMH-2177 & 2.4 & 2.0 & 2.2 & 2.0 & 3.0 & 2.5 \\
\hline KDMH 2705 & 1.9 & 2.0 & 2.0 & 1.8 & 3.0 & 2.4 \\
\hline KNMH 4010131 & 1.8 & 1.5 & 1.7 & 2.2 & 2.5 & 2.4 \\
\hline DKC 9145 (IJ8533) & 2.1 & 2.0 & 2.1 & 3.3 & 3.0 & 3.2 \\
\hline Rasi-3033 & 2.2 & 2.0 & 2.1 & 2.4 & 3.0 & 2.7 \\
\hline PMH 4 & 2.3 & 2.0 & 2.2 & 2.2 & 3.5 & 2.9 \\
\hline Bio -9637 & 1.8 & 2.0 & 1.9 & 2.3 & 3.0 & 2.7 \\
\hline HM 4 & 2.1 & 2.0 & 2.1 & 2.2 & 2.0 & 2.1 \\
\hline HM 8 & 2.3 & 2.0 & 2.2 & 2.2 & 3.0 & 2.6 \\
\hline HM 9 & 2.0 & 2.0 & 2.0 & 2.0 & 3.0 & 2.5 \\
\hline RES. CHECK & 1.1 & - & 1.1 & 1.9 & - & 1.9 \\
\hline SUS. CHECK & 3.6 & 4.5 & 4.1 & 3.9 & 4.0 & 4.0 \\
\hline
\end{tabular}


Table 2. Performance of different maize hybrids of early and extra early maturity group to MLB and BLSB diseases over the locations.

\begin{tabular}{|c|c|c|c|c|c|c|}
\hline Genotype (EM) & $\begin{array}{c}\text { MLB Score } \\
\text { Karnal }\end{array}$ & $\begin{array}{c}\text { BLSB Score } \\
\text { Delhi }\end{array}$ & Average & Karnal & Delhi & Average \\
\hline $\mathrm{AH} 1261$ & 1.6 & 3.0 & 2.3 & 3.3 & 3.0 & 3.2 \\
\hline DMH-63 & 2.7 & 4.5 & 3.6 & 2.9 & 2.0 & 2.5 \\
\hline FH 3664 & 2.5 & 2.0 & 2.3 & 2.4 & 3.5 & 3.0 \\
\hline FH 3669 & 1.4 & 2.0 & 1.7 & 2.4 & 3.5 & 3.0 \\
\hline $\mathrm{JH}-31610$ & 3.3 & 2.5 & 2.9 & 2.5 & 3.0 & 2.8 \\
\hline LG 31.81 & 3.1 & 2.5 & 2.8 & 2.9 & 3.5 & 3.2 \\
\hline MEH 1-12-13 & 2.8 & 2.0 & 2.4 & 2.9 & 2.0 & 2.5 \\
\hline Bio 9720 & 2.1 & 1.5 & 1.8 & 2.4 & 3.0 & 2.7 \\
\hline GWH 0712 & 2.9 & 3.0 & 3.0 & 4.1 & 4.0 & 4.1 \\
\hline CMH 11-579 & 3.1 & 2.0 & 2.6 & 2.5 & 3.0 & 2.8 \\
\hline CMH 11-595 & 1.8 & 3.0 & 2.4 & 4.1 & 3.0 & 3.6 \\
\hline CMH 11-611 & 1.9 & 1.5 & 1.7 & 2.4 & 3.0 & 2.7 \\
\hline CMH 11-626 & 1.8 & 1.5 & 1.7 & 3.5 & 3.5 & 3.5 \\
\hline CMH 11-629 & 2.3 & 2.0 & 2.2 & 2.1 & 3.0 & 2.6 \\
\hline$B-52$ & 2.0 & 2.0 & 2.0 & 3.1 & 2.5 & 2.8 \\
\hline $\mathrm{EH}-2214$ & 2.0 & 2.0 & 2.0 & 3.6 & 3.0 & 3.3 \\
\hline $\mathrm{NMH}-1258$ & 1.6 & 1.5 & 1.6 & 3.3 & 3.0 & 3.2 \\
\hline HKH341 & 3.2 & 2.0 & 2.6 & 3.1 & 2.0 & 2.6 \\
\hline EH-2233 & 2.3 & 2.5 & 2.4 & 2.4 & 3.0 & 2.7 \\
\hline JH-31613 & 2.3 & 1.5 & 1.9 & 2.4 & 2.5 & 2.5 \\
\hline EH-2212 & 2.0 & 2.0 & 2.0 & 3.7 & 3.0 & 3.4 \\
\hline FH 3605 & 2.4 & 2.0 & 2.2 & 3.2 & 3.5 & 3.4 \\
\hline FH 3626 & 2.2 & 2.0 & 2.1 & 3.5 & 3.5 & 3.5 \\
\hline KMH-7021 & 3.1 & 2.0 & 2.6 & 4.0 & 4.0 & 4.0 \\
\hline CMH 10-531 & 3.2 & 3.0 & 3.1 & 3.9 & 3.0 & 3.5 \\
\hline Prakash & 3.0 & 2.0 & 2.5 & 3.6 & 2.5 & 3.1 \\
\hline RES. CHECK & 1.5 & - & 1.5 & 1.3 & - & 1.3 \\
\hline SUS. CHECK & 4.2 & 4.5 & 4.4 & 3.5 & 4.0 & 3.8 \\
\hline \multicolumn{7}{|l|}{ Genotype (EEM) } \\
\hline APQH 9 & 2.0 & 2.0 & 2.0 & 2.3 & 3.0 & 2.7 \\
\hline $\mathrm{AH}-1212$ & 2.3 & 3.0 & 2.7 & 2.3 & 3.5 & 2.9 \\
\hline KH-7502 & 1.8 & 2.5 & 2.2 & 2.2 & 3.0 & 2.6 \\
\hline Vivek Hybrid-21 & 1.8 & 2.0 & 1.9 & 3.4 & 4.0 & 3.7 \\
\hline Vivek Hybrid-43 & 2.2 & 2.0 & 2.1 & 4.1 & 4.0 & 4.1 \\
\hline VIVEK QPM 9 & 2.1 & 2.5 & 2.3 & 2.4 & 4.0 & 3.2 \\
\hline $\mathrm{PMH}-1-\mathrm{F}$ & 1.8 & 2.0 & 1.9 & 4.1 & 3.0 & 3.6 \\
\hline BIO 9681-F & 3.4 & 3.0 & 3.2 & 4.0 & 3.0 & 3.5 \\
\hline PMH 3-F & 1.6 & 1.5 & 1.6 & 3.4 & 3.0 & 3.2 \\
\hline HM 10-F & 2.4 & 2.0 & 2.2 & 2.1 & 3.0 & 2.6 \\
\hline RES. CHECK & 1.5 & - & 1.5 & 1.6 & - & 1.6 \\
\hline SUS. CHECK & 4.0 & 4.5 & 4.3 & 3.4 & 4.0 & 3.7 \\
\hline
\end{tabular}

as moderately susceptible to banded leaf and sheath blight disease.

In past also, germplasm evaluation had been carried out using a large number of maize varieties, hybrids and inbred lines in order to find out the sources of resistance. Kaur et al. (2010) evaluated twenty inbred lines and reported $\mathrm{E}-10$ as resistant to maydis leaf blight and charcoal rot. Earlier various workers had identified inbred lines namely, CM 104 and CM 105 as resistant sources to MLB (Sharma et al., 2003). Over 800 open-pollinated (OP) varieties of sweet corn were grown and compared for their reactions to Stewart's wilt, common rust, northern leaf blight (NLB), and southern leaf blight (SLB) by Pataky et al. (1998). Recently, Kumar et al. (2013) has reported maydis leaf blight in the range of 2.0 to 4.0 on seventeen 
Table 3. Performance of different specialty corn hybrids to MLB and BLSB diseases over the locations

\begin{tabular}{|c|c|c|c|c|c|c|}
\hline \multirow[t]{2}{*}{ Genotype } & \multicolumn{3}{|c|}{ MLB Score } & \multicolumn{3}{|c|}{ BLSB Score } \\
\hline & Karnal & Delhi & Average & Karnal & Delhi & Average \\
\hline \multicolumn{7}{|l|}{ QPM } \\
\hline BAU QMH-17 & 2.3 & 2.0 & 2.2 & 2.7 & 3.5 & 3.1 \\
\hline BQPMH 18 & 2.0 & 2.0 & 2.0 & 2.7 & 3.5 & 3.1 \\
\hline BQPMH 36 & 2.8 & 2.0 & 2.4 & 4.1 & 3.5 & 3.8 \\
\hline KDQH-49 & 2.4 & 2.0 & 2.2 & 3.0 & 3.5 & 3.3 \\
\hline LQPMH 114 & 3.2 & 2.0 & 2.6 & 2.5 & 3.0 & 2.8 \\
\hline LQPMH 214 & 3.2 & 2.0 & 2.6 & 2.0 & 2.5 & 2.3 \\
\hline LQPMH 314 & 1.4 & 2.0 & 1.7 & 1.8 & 3.5 & 2.7 \\
\hline OQPMH 11-6 & 2.7 & 2.0 & 2.4 & 3.3 & 3.5 & 3.4 \\
\hline VEHQ 11-1 & 2.2 & 2.0 & 2.1 & 1.9 & 3.5 & 2.7 \\
\hline VEHQ 14-1 & 1.5 & 2.0 & 1.8 & 3.0 & 3.5 & 3.3 \\
\hline DMRQPM1401 & 2.0 & 2.0 & 2.0 & 1.9 & 4.0 & 3.0 \\
\hline MMH QPM-6-12-13 & 2.2 & 2.5 & 2.4 & 3.5 & 3.5 & 3.5 \\
\hline HQPM1 & 2.9 & 2.0 & 2.5 & 2.2 & 2.5 & 2.4 \\
\hline HQPM4 & 2.8 & 1.5 & 2.2 & 2.1 & 2.5 & 2.3 \\
\hline HQPM5 & 1.7 & 2.5 & 2.1 & 2.3 & 3.5 & 2.9 \\
\hline Vivek QPM-9 & 1.9 & 2.0 & 2.0 & 4.0 & 4.0 & 4.0 \\
\hline \multicolumn{7}{|l|}{ PC } \\
\hline Pop corn (SCH) & 2.6 & 3.0 & 2.8 & 3.3 & 4.0 & 3.7 \\
\hline Bajaura Popcorn-2 & 3.4 & 3.5 & 3.5 & 2.4 & 4.0 & 3.2 \\
\hline BPC 3 & 2.1 & 3.0 & 2.6 & 2.1 & 3.5 & 2.8 \\
\hline BPCH 27 & 1.5 & 3.0 & 2.3 & 2.3 & 3.0 & 2.7 \\
\hline KDPC-2 & 3.2 & 3.0 & 3.1 & 2.0 & 3.0 & 2.5 \\
\hline DMRHP 1402 & 3.1 & 3.0 & 3.1 & 3.7 & 4.0 & 3.9 \\
\hline VL Pop Corn-2 & 3.2 & 2.5 & 2.9 & 3.0 & 3.0 & 3.0 \\
\hline HPC 1 & 3.3 & 2.0 & 2.7 & 1.7 & 3.5 & 2.6 \\
\hline VL Pop corn & 3.2 & 3.0 & 3.1 & 3.3 & 3.5 & 3.4 \\
\hline \multicolumn{7}{|l|}{ SC } \\
\hline ADVSW -1 & 2.8 & 1.5 & 2.2 & 2.0 & 3.0 & 2.5 \\
\hline ADVSW -2 & 1.4 & 2.0 & 1.7 & 2.0 & 3.5 & 2.8 \\
\hline ASKH 1 & 3.1 & 2.0 & 2.6 & 2.9 & 3.5 & 3.2 \\
\hline Bajaura Sweet Corn & 3.2 & 2.5 & 2.9 & 2.9 & 3.5 & 3.2 \\
\hline Bisco MaDHAU & 2.5 & 2.0 & 2.3 & 1.9 & 3.5 & 2.7 \\
\hline $\mathrm{BSCH} 6$ & 2.3 & 2.5 & 2.4 & 2.3 & 4.5 & 3.4 \\
\hline $\mathrm{BSCH} 63$ & 3.0 & 2.0 & 2.5 & 2.2 & 3.5 & 2.9 \\
\hline FSCH 18 & 2.8 & 2.0 & 2.4 & 2.4 & 4.0 & 3.2 \\
\hline $\mathrm{FSCH} 41$ & 2.6 & 2.5 & 2.6 & 2.6 & 4.0 & 3.3 \\
\hline FSCH 55 & 2.5 & 2.0 & 2.3 & 3.2 & 3.5 & 3.4 \\
\hline KSCH-333 & 1.4 & 1.5 & 1.5 & 3.3 & 3.0 & 3.2 \\
\hline QMHSC-1182 & 2.0 & 3.0 & 2.5 & 3.1 & 4.0 & 3.6 \\
\hline SWC 001 & 2.8 & 2.0 & 2.4 & 1.9 & 3.0 & 2.5 \\
\hline MADHAURI & 2.4 & 2.5 & 2.5 & 1.8 & 4.0 & 2.9 \\
\hline WOSC & 3.3 & 2.5 & 2.9 & 2.1 & 3.5 & 2.8 \\
\hline \multicolumn{7}{|l|}{ BC } \\
\hline ASKBH-1 & 2.0 & 2.0 & 2.0 & 1.7 & 3.5 & 2.6 \\
\hline BVM-2 & 3.3 & 2.5 & 2.9 & 2.0 & 4.0 & 3.0 \\
\hline $\mathrm{CMH} 11-658$ & 1.8 & - & 1.8 & 2.0 & - & 2.0 \\
\hline CMH 11-659 & 1.3 & 2.0 & 1.7 & 3.1 & 3.5 & 3.3 \\
\hline NP 5004 & 2.5 & 2.5 & 2.5 & 2.6 & 4.5 & 3.6 \\
\hline NP 5040 & 1.4 & 2.5 & 2.0 & 3.3 & 4.5 & 3.9 \\
\hline Vivek Hybrid-27 & 2.2 & 2.0 & 2.1 & 2.8 & 3.5 & 3.2 \\
\hline $\mathrm{HM} 4$ & 2.3 & 2.5 & 2.4 & 4.1 & 3.0 & 3.6 \\
\hline RES. CHECK & 1.6 & - & 1.6 & 1.8 & - & 1.8 \\
\hline SUS. CHECK & 4.1 & 5.0 & 4.6 & 4.2 & 4.0 & 4.1 \\
\hline
\end{tabular}


QPM lines under test at Ludhiana. On the other hand Garg et al. (2007) analyzed 29 inbred lines of maize and found only one genotype (CA00106) as moderately resistance to BLSB and the remaining were highly susceptible. Bhavana and Gadag (2009) also did multi location screening of different maize genotypes for resistance to BLSB disease under artificial inoculation conditions and recorded $27 \%$ and $13 \%$ resistant lines at Pantnagar and Udaipur, respectively. Bhavana and Gadag (2011) again evauated 40 lines for resistance against banded leaf and sheath blight of maize but none was found resistance indicating the paucity of resistance lines. Recently, Madhavi et al. (2012) evaluated sixteen maize genotypes, including 12 inbred lines, where inbred line namely $\mathrm{BH} 11$ showed moderate resistance to the disease. Kapoor and Lata (2013) have also reported some crosses viz. V348 x CM126, V354 x CM212, V356 x CM200, V356 x CM212 and KI-24 x CM200 as source of resistance to banded leaf and sheath blight. As has been observed in present studies, plant resistance to Indian pathotypes of $B$. sorokiniana and $R$. solani has also been reported in some of the cultivars and inbred lines (Anonymous, 2014). Malik et al. (2015) identified five quality protein maize inbreds namely DQL 2006, DQL 2009, DQL 2025, DQL 2031 AND DQL 2071 as source of resistance to MLB and BLSB. Malik (2016) also recorded four out thirty elite inbred lines as resistant to BLSB.

Present investigation conclude that among the ninety four normal yellow maize hybrids, thirty six hybrids (fourteen for LM; twelve for MM; seven for EM and three for EEM group) exhibited moderately resistant reaction to maydis leaf blight and banded leaf and sheath blight diseases. DAS-MH-105 of late maturity group was observed as resistant to MLB and BLSB. CMH 10-531 of early maturity group was found moderately susceptible to both the diseases. Specialty corn hybrids including (HQPM1 for quality protein maize; HPC 1 for pop corn; ADVSW-1 for sweet corn and BVM-2 for baby corn) were found moderately resistant against MLB and BLSB diseases.

\section{ACKNOWLEDGEMENTS}

All sort of assistance rendered by Director, ICAR-Indian Institute of Maize Research, New Delhi and Director of Research, Chaudhary Charan Singh Haryana Agricultural University, Hisar for the above study is gratefully acknowledged.

\section{REFERENCES}

Anonymous (2014). Annual Progress Report Kharif Maize 2014. All India Co-ordinated Maize Improvement Project, Indian Institute of Maize Research, New Delhi, pp. 1-260.

Anonymous (2015). Statistical Abstract of Haryana 2012-13. Published by Department of Economic and Statistical Analysis, Haryana, pp. 239-252.

Balint-Kurti PJ and Johal GS (2009). Maize disease resistance. In: Handbook of maize: its biology. editors: Bennetzen, J.L., Hake, S.C., Springer New York, 229-250.
Bhavana P and Gadag RN (2009). Evaluation of maize genotypes for resistance to banded leaf and Sheath blight. Ann. Plant Protect. Sci. 17(2): 459-526.

Bhavana P and Gadag RN (2011). Identifying sources of resistance to banded leaf and Sheath blight of maize. Indian Phytopath. 64: 308-309.

Garg A, Prasanna BM, Sharma RC, Rathore RS and Saxena SC (2007). Identification of resistance sources to banded leaf and sheath blight (Rhizoctonia solanif. sp. sasaki) in maize. Indian Phytopath. 60: 162-166.

Kapoor C and Lata S (2013). Screening of some maize (Zea mays L.) inbreds for conversion to quality protein maize lines. Indian J. Agr. Res. 47: 457-460.

Kaur H, Malhi NS and Chawla JS (2010). Evaluation of maize genotypes for resistance to Maydis leaf blight and Charcoal rot under artificial epiphytotic conditions. Indian Phytopath. 63: 21-22.

Kumar R, Hooda KS, Olakh DS, Kaur H, Malik V and Kumar S (2013). Reaction of QPM Inbred Lines against Maydis Leaf Blight (MLB) and Charcol Rot. Electronic J. Plant Breed. 4: 1280-1283.

Kumar R and Singh IS (2004). Genetic control of banded leaf and sheath blight (Rhizoctonia solanif. sp. sasakii) in maize (Zea mays L.). Cereal Res. Comm. 32: 309-316.

Madhavi M, Reddy PN, Reddy RR and Sudarshan MR (2012). Evaluation of maize genotypes against banded leaf and sheath blight disease incited by Rhizoctonia solani f. sp. sasakii (Kuhn) Exner. J. Res. ANGRAU 40: 20-23.

Malik VK (2016). Performance of maize germplasms against BLSB disease incited by Rhizoctonia solani f.sp. sasakii. Indian Phytopath. 69: 97-98.

Malik VK, Kumar R, Jaglan MS and Kamboj MC (2015). Identification of new sources of resistance against maydis leaf blight (MLB) and banded leaf and sheath blight (BLSB) diseases in quality protein maize. Progressive Res - an Int. J. 10: 606-608.

Oerke EC (2006). Crop losses to pests. J. Agr. Sci. 144(1): 3143.

Pataky JK, Toit L Jdu, Revilla P and Tracy WF (1998). Reactions of open-pollinated sweet corn cultivars to Stewart's wilt, common rust, Northern leafblight, and Southern leafblight. Plant Dis. 82: 939-944.

Payak MM and Sharma RC (1985). Maize diseases and their approach to their management. Trop. Pest Manage. 31: 302-310.

Sharma RR, Gour HN, Bora KK and Gaur RB (2002). Lipid peroxidation and defense related enzymes in maize infected by Rhizoctonia solani. Indian Phytopath. 55: 486487.

Sharma RC, Rai SN, Mukherjee and Gupta NP (2003). Assessing Potential of Resistance Source for the Enhancement of Resistance to Maydis Leaf Blight (Bipolaris Maydis) in Maize (Zea mays L.). Indian J. Genet. Plant Breed. 63: 33-36.

Shekhar M and Kumar S (2012). In: Inoculation methods and disease rating scales for maize diseases. Second edition (Revised), Directorate of Maize Research, Pusa Campus, New Delhi, pp. 11-14.

Singh R, Mani VP, Koranga KS, Bisht GS, Khandelwal RS, Bhandari P and Pant SK (2004). Identification of additional sources of resistance to Exserohilum turcicum in maize (Zea mays L.). SABRAO J. Breed. Genet. 36: 45-47.

White DG (1999). In: Compendium of Corn Diseases, 3rd ed., Amer. Phytopathol. Soc., St. Paul, MN. 